\title{
ANALISIS KEKUATAN MEKANIK DESAIN BEJANA MOLECULAR SIEVE
}

\author{
Dedy Haryanto, Ainur Rosidi, G.Bambang Heru K., Giarno, Joko P. Witoko, \\ Pusat Teknologi dan Keselamatan Reaktor Nuklir, \\ Kawasan Puspiptek Serpong, Tangerang Selatan, 15314, Indonesia \\ Email:haryanto_dedyaja@yahoo.co.id
}

\begin{abstract}
ABSTRAK
ANALISIS KEKUATAN MEKANIK DESAIN BEJANA MOLECULAR SIEVE. Reaktor Daya Eksperimental (RDE) menggunakan bahan bakar bola (pebble) dan gas helium sebagai pendingin primernya. Untuk mempertahankan dan menjaga kualitas helium sebagai pendingin sesuai persyaratannya maka dirancang fasilitas Sistem Pemurnian Helium (SPH). Salah satu bagian dari komponen utama fasilitas Sistem Pemurnian Helium ini adalah bejana molecular sieve. Fungsi dari molecular sieve ini untuk menyerap gas $\mathrm{CO}_{2}, \mathrm{CH}_{4}$, dan $\mathrm{H}_{2} \mathrm{O}$. Tujuan penelitian ini adalah untuk mengetahui kemampuan kekuatan mekanik dari bejana molecular sieve melalui simulasi menggunakan software Computer Aided Three-dimensional Interactive Application (CATIA). Tahapan yang dilakukan dalam menganalisis kekuatan mekanik desain molecular sieve meliputi : pembuatan model 3-dimensi, memasukkan data sifat mekanik material SS304, serta mensimulasikan pengoperasian pada tekanan uji dan temperatur bervariasi. Pada tekanan 30 bar dan temperatur $120{ }^{\circ} \mathrm{C}$ tegangan mekanik yang dihasilkan sebesar 4,4608 $\times 10^{7} \mathrm{~N} / \mathrm{m}^{2}$ lebih kecil daripada yield strenght material SS 304 dan berada di daerah elastis material. Sedangkan translational displacement sebesar 1,1375 mm sangat kecil jika dibandingkan dengan dimensi bejana molecular sieve sehingga tidak mengakibatkan perubahan bentuk. Dengan demikian bejana molecular sieve aman untuk dioperasikan guna mendukung penelitian pemurnian helium
\end{abstract}

Kata kunci: bejana molecular sieve, tegangan mekanik, translational displacement, CATIA

\section{ABSTRACT}

MECHANICAL STRENGTH ANALYSIS OF MOLECULAR SIEVE VESSEL DESIGN. The Experimental Power Reactor (EPR) uses pebble bed reactor fuel and helium gas as its primary coolant. To maintain the helium quality below its limits requirements the helium purification system (HPS) is designed. One part of the HPS main component is molecular sieve vessel. In this vessel, the molecular sieve adsorption $\mathrm{CO}_{2}, \mathrm{CH}_{4}$, and $\mathrm{H}_{2} \mathrm{O}$. The purpose of this research is to determine the mechanical strength of molecular sieve vessel through simulation testing using Computer Aided Three-dimensional Interactive Application (CATIA). Several stages should be performed in analyzing the mechanical strength of molecular sieve is: 3-dimensional modeling, data input on the mechanical properties of the SS 304, and simulation at various operating temperature and pressures. At 30 bar and $120{ }^{\circ} \mathrm{C}$, the mechanical stress of molecular sieve vessel is $4.4608 \times 10^{7} \mathrm{~N} / \mathrm{m}^{2}$ lower than the yield strength and still in the elastic region of SS 304. The translational displacement value is $1.1375 \mathrm{~mm}$ very small when compared to the dimensions of molecular sieve vessel. This value does not result in a vessel shape change. Thus the molecular sieve vessel is safe to operate to support research on the helium purification.

Keywords: molecular sieve vessel, mechanical stress, translational displacement, CATIA 


\section{PENDAHULUAN}

Peningkatan pembangunan di bidang teknologi, industri dan informasi yang semakin pesat di Indonesia berakibat pada meningkatnya konsumi energi, khususnya energi listrik. Besarnya kebutuhan ini tidak dibarengi dengan supply energi yang di sediakan, sehingga krisis energi akan terus terjadi. Oleh karena itu diperlukan upaya pengembangan energi baru terbarukan untuk mengurangi krisis energi tersebut. Batan Tenaga Nuklir Nasional (BATAN) sebagai lembaga penelitian dan pengembangan energi nuklir merencanakan pembangunan Reaktor Daya Eksperimental (RDE) yang bersifat non-komersial. Dalam pembangunan RDE dipilih teknologi jenis Pebble Bed Reactor (PBR) dengan pertimbangan sangat aman, berfungsi untuk kogenerasi, mempunyai fleksibiltas bahan bakar, telah teruji, harga kompetitif, multiguna, dapat dikembangkan di seluruh wilayah Indonesia sesuai kebutuhannya, dan untuk memenuhi kebutuhan penyediaan listrik.

Berdasar desain konseptual RDE yang telah dibuat oleh BATAN, gas helium digunakan sebagai pendingin primer dan air digunakan sebagai pendingin sekunder. Panas pendingin primer dipindahkan ke pendingin sekunder melalui steam generator. Kemurnian helium pada pendingin primer harus selalu dijaga pada batas tertentu sehingga dampak ke sistem, struktur dan komponen (SSK) adalah minimal. Untuk memenuhi persyaratan kemurnian helium yang diinginkan pada pendingin primer RDE dibutuhkan sistem pemurnian helium (SPH) [1]. Sistem ini harus dirancang mampu memurnikan helium dari pengotor padatan dan gas.

Penumpukan pengotor debu grafit pada SSK akan berdampak pada berkurangnya proses pengambilan panas. Pengotor berbentuk gas jika terbawa dalam aliran pendingin akan memicu terjadinya proses karburisasi dan dekarburisasi pada material. Proses karburasi pada SSK akan membuat material lebih rapuh (brittle) [2] sedangkan proses dekarburisasi akan menurunkan konsentrasi karbon pada material dan menghalangi terbentuknya lapisan oksida pada permukaan sehingga mudah terjadi proses korosi.

Komponen utama yang digunakan pada SPH-RDE adalah filter, bejana oksidasi $\mathrm{CuO}$, kondensor (water cooler), bejana molecular sieve dan bejana karbon aktif temperatur sangat rendah (cryogenic). Berdasarkan pengalaman pengoperasian reaktor HTGR di China (HTR-10) dan Jepang (HTTR) prinsip pembersihan pengotor gas $\mathrm{CO}_{2}, \mathrm{CH}_{4}$ dan $\mathrm{H}_{2} \mathrm{O}$ adalah menggunakan molecular sieve [3, 4]. Beberapa penelitian tentang pembersihan pengotor gas menggunakan molecular sieve telah dilakukan oleh beberapa peneliti diantaranya adalah Myrlla et.al yang 
melakukan penelitian untuk mempelajari perilaku dinamis molecular Zeolite 4A untuk mengurangi pengotor $\mathrm{CO}_{2}$ di gas alam pada tekanan tinggi menggunakan simulasi software Adsim Aspen [5]. Xiaojing et.al, melakukan eksperimen untuk karakterisasi molecular sieve pada beberapa ukuran untuk menyerap hidrogen pada tekanan $100 \mathrm{~Pa}, 200 \mathrm{~Pa}$, dan 0,2 MPa. Hasil menunjukkan bahwa molecular sieve 5A-2 dapat secara efektif menyerap hidrogen dengan cepat [6]. Ahmed et.al, melakukan perhitungan teori dan eksperimen untuk pemisahan propana dari campuran metana, etana, dan propana menggunakan zeolite molecular sieve 4A sebagai adsorben. Hasil eksperimen menunjukkan kemurnian propana yang diperoleh $98 \%$ dan produktivitasnya $0,413 \mathrm{mmol} /$ menit [7].

Parameter yang menentukan efisiensi proses pembersihan pada molecular sieve adalah lama kontak gas dengan molecular sieve dan jenis molecular sieve yang digunakan. Untuk mendapatkan efisiensi proses pembersihan yang optimal, selain menggunakan tipe molecular sieve yang cocok maka akan dihitung pula dimensi kolom/bed molecular sieve yang tepat. Dimensi yang tidak tepat pada rancangan kolom molecular sieve berdampak pada biaya sehingga secara ekonomis tidak menguntungkan

Penelitian ini bertujuan untuk mengetahui kemampuan dari desain bejana molecular sieve dari segi kekuatan mekaniknya melalui pengujian secara simulasi menggunakan software Computer Aided Three-dimensional Interactive Application (CATIA). Kekuatan mekanik meliputi tegangan mekanik (stress) dan translation displacement pada Bejana Molecular Sieve akibat pembebanan. Pembebanan berupa tekanan dan temperatur yaitu tekanan operasional 30 bar dan temperatur operasional $100{ }^{\circ} \mathrm{C}$ [8]. Tahapan yang dilakukan dalam menganalisis kekuatan mekanik bejana molecular sieve meliputi pembuatan model 3-dimensi bejana molecular sieve, mengumpulkan data sifatsifat mekanik material bejana molecular sieve yang digunakan dan melakukan simulasi kekuatan mekanik [9]. Dengan membandingkan besar tegangan mekanik yang dialami oleh bejana molecular sieve ketika diberi beban terhadap yield strenght material yang digunakan maka dapat diketahui kekuatan mekanik bejana molecular sieve, dan diharapkan translation displacement yang terjadi sangat kecil. Software ini juga pernah digunakan untuk menganalisis struktur fasilitas eksperimen kanal dan support perangkat sumber pemanas $[10,11]$.

\section{DESAIN BEJANA MOLECULAR SIEVE}

Desain dari bejana molecular sieve ditunjukkan pada Gambar 1, terdiri dari 
komponen tutup, badan bejana (vessel), pemipaan dan rumah termokopel

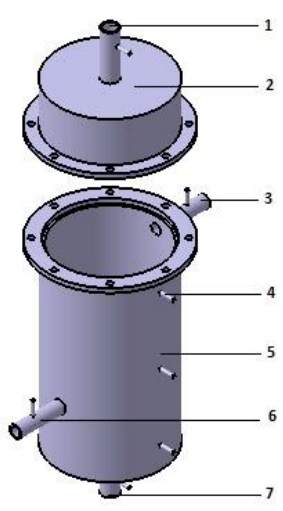

Keterangan :

1. Pemipaan input operasi normal

3. Pemipaan input operasi regenerasi

4. Rumah termokopel

5. Body bejana (vessel)

6. Pemipaan output operasi regenerasi

7. Pemipaan output operasi normal

Gambar 1. Desain bejana molecular sieve

Desain bejana molecular sieve mempunyai pemipaan gas helium untuk operasi normal dan operasi regenerasi. Pemipaan operasi normal input dan output gas helium menggunakan tube $\varnothing 1$ inchi Sch. 40, sedangkan pemipaan operasi regenerasi
2. Tutup bejana

input dan output menggunakan tube $\varnothing$ 3/4 inchi Sch. 40. Badan dan tutup bejana molecular sieve menggunakan Pipa $\varnothing 10$ inchi dengan ketebalan bervariasi dikarenakan di dalam vessel tersebut terdapat filter yang berfungsi sebagai tempat pelet molecular sieve. Pada bejana molecular sieve dan pemipaan dilengkapi dengan rumah termokopel yang berfungsi untuk pemasangan kabel termokopel terkait dengan pengambilan data yang diperlukan. Data tersebut dapat berupa data tekanan dan temperatur di dalam bejana molecular sieve. Bejana molecular sieve didesain menggunakan material stainless steel 304 dengan dimensi dan bentuk seperti ditunjukkan pada Gambar 2 berikut.

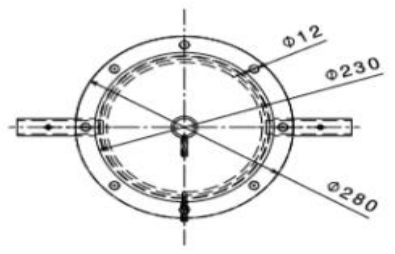

Top view
Scale: $1: 5$

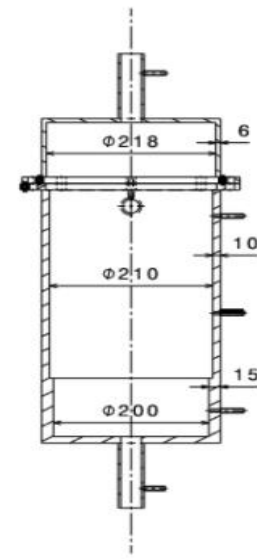

Section view A-A
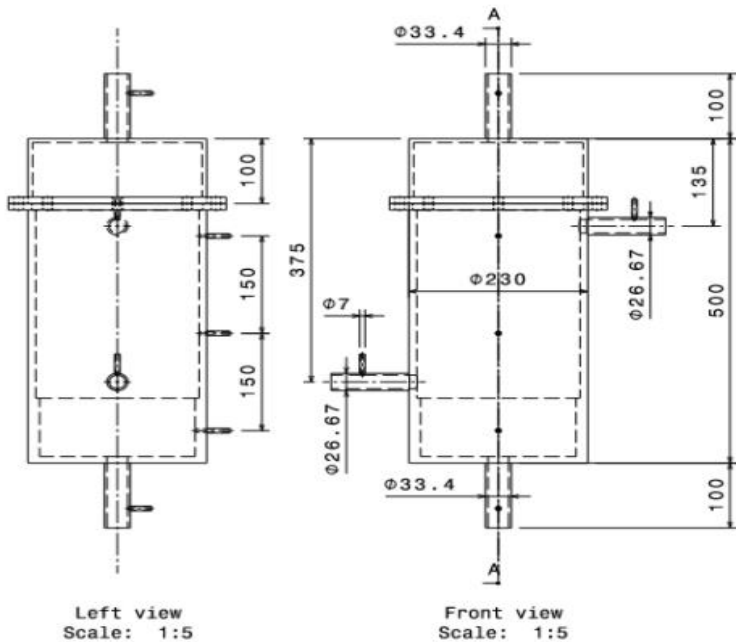

Gambar 2. Dimensi dan bentuk bejana molecular sieve 
Dalam pengujian secara simulasi untuk mengetahui kekuatan mekanik suatu desain diperlukan data masukan berupa sifat mekanik dari material yang digunakan. Sifat mekanik dari material SS 304 adalah sebagai berikut ;

Tabel 1. Sifat mekanik bahan dan Stainless Steel 304 [12]

\begin{tabular}{ll}
\hline \multicolumn{1}{c}{ Parameter } & \multicolumn{1}{c}{ Nilai } \\
\hline Young Modulus & $1,93 \times 10^{11} \mathrm{~N} / \mathrm{m}^{2}$ \\
Poisson Ratio & 0,29 \\
Density & $7800 \mathrm{~kg} / \mathrm{m}^{3}$ \\
Thermal Expantion & $1,72 \times 10^{-5} \mathrm{~K}^{-1}$ \\
Yield Strength & $1,7 \times 10^{8} \mathrm{~N} / \mathrm{m}^{2}$ \\
\hline
\end{tabular}

Dengan menggunakan pemodelan 3-dimensi desain bejana molecular sieve serta sifatsifat mekanik stainless steel 304 sebagai data masukkan pada software CATIA. Maka dengan pengujian secara simulasi dapat diketahui kekuatan mekanik meliputi tegangan mekanik dan translasional displacement pada desain bejana molecular sieve.

\section{METODOLOGI}

Tahapan pengujian secara simulasi yang dilakukan dalam menganalisis kekuatan mekanik adalah sebagai berikut ;

1. Pembuatan model 3-dimensi.

Pada tahapan ini dilakukan pembuatan model 3-dimensi bejana molecular sieve dengan mengacu pada desain. Model tersebut dilengkapi dengan sifatsifat material yang digunakan pada desain sebagai data masukan.

2. Pembebanan.
Pembebanan maksimal yang diberikan pada bejana molecular sieve adalah berupa tekanan dan temperatur. Pembebanan diberikan dengan tekanan bervariasi sebesar 10 bar, 30 bar, 50 bar dan 70 bar. Temperatur bervariasi mulai dari $30{ }^{\circ} \mathrm{C}$ sampai dengan 150 ${ }^{\circ} \mathrm{C}$. Beban diberikan lebih besar $100 \%$ sampai dengan $150 \%$ dari beban operasional, bertujuan untuk mengetahui keandalan dan keamanan desain. Tekanan operasi bejana molecular sieve 30 bar dan temperatur operasi $100{ }^{\circ} \mathrm{C}$.

\section{Restrain.}

Restrain mensimulasikan model 3dimensi body dan support pada kondisi statis. Restrain harus diberikan pada model agar simulasi dapat dilakukan.

4. Pengujian tegangan mekanik dan traslational displacement.

Model 3-dimensi diberikan input berupa sifat-sifat material, beban dan restrain. Selanjutnya dilakukan simulasi untuk mengetahui besaran tegangan mekanik dan translasional displacement yang terjadi. Besaran tegangan mekanik dibandingkan dengan yield strength material yang digunakan sehingga dapat diketahui kekuatan mekanik desain bejana molecular sieve. 


\section{HASIL DAN PEMBAHASAN}

Pengujian secara simulasi dilakukan pada desain bejana molecular sieve dengan hasil simulasi yang diperoleh adalah sebagai berikut :

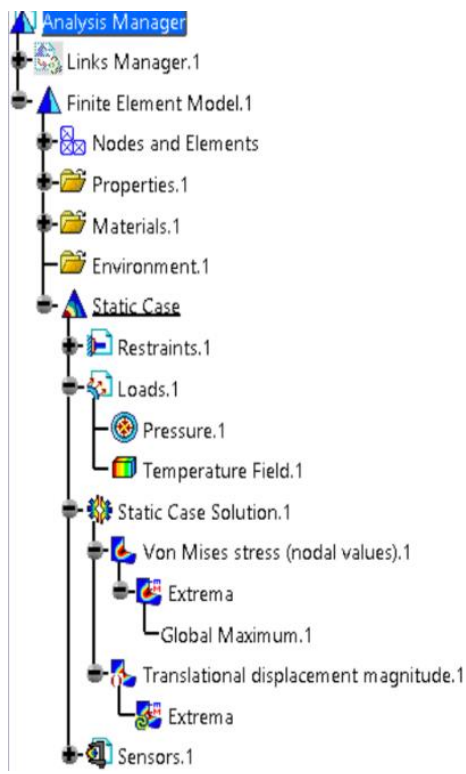

Hasil pengujian secara simulasi untuk mengetahui tegangan mekanik dengan beban berupa tekanan sebesar 30 bar dan temperatur sebesar $90{ }^{\circ} \mathrm{C}$ ditunjukkan pada Gambar 3.
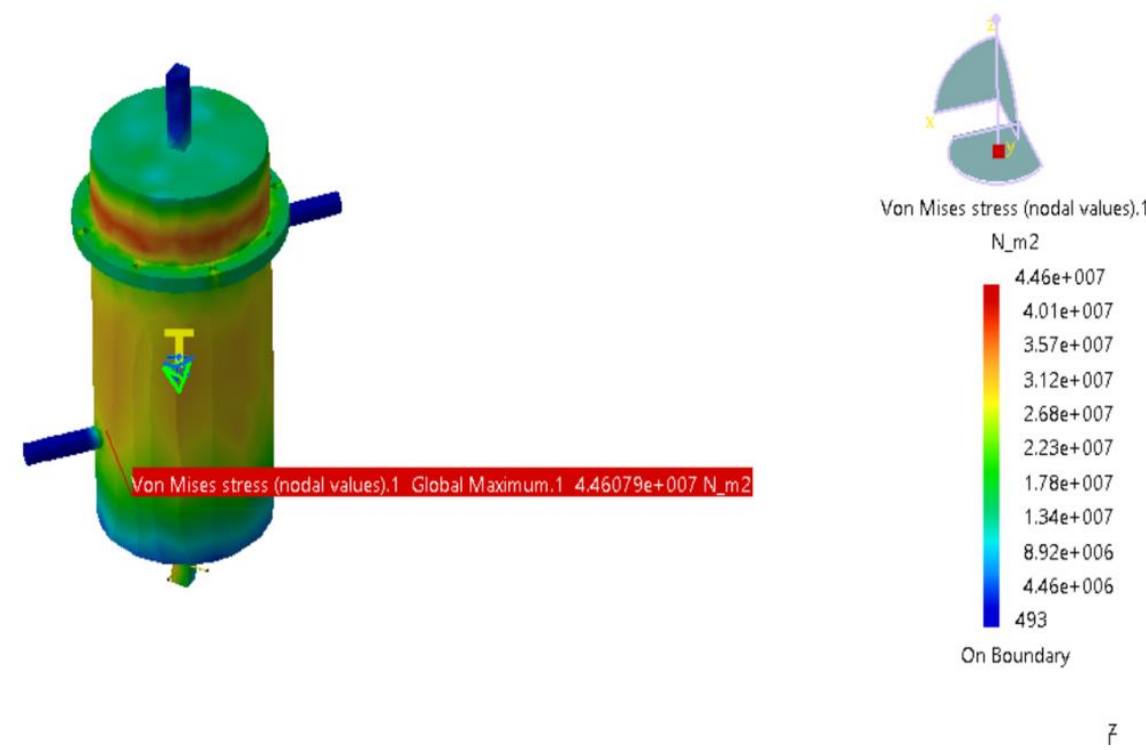

Gambar 3. Tegangan mekanik yang terjadi pada desain bejana molecular sieve.

Hasil pengujian secara simulasi untuk mengetahui besar translational displacement yang terjadi pada desain bejana molecular sieve ditunjukkan pada Gambar 4. Pengujian ini bertujuan untuk mengetahui terjadinya perubahan bentuk pada desain bejana molecular sieve. Jika hasil pengujian memperoleh translational displacement yang sangat besar dibandingkan dengan ukuran desain bejana molecular sieve, maka telah terjadi perubahan bentuk pada desain bejana molecular sieve. 

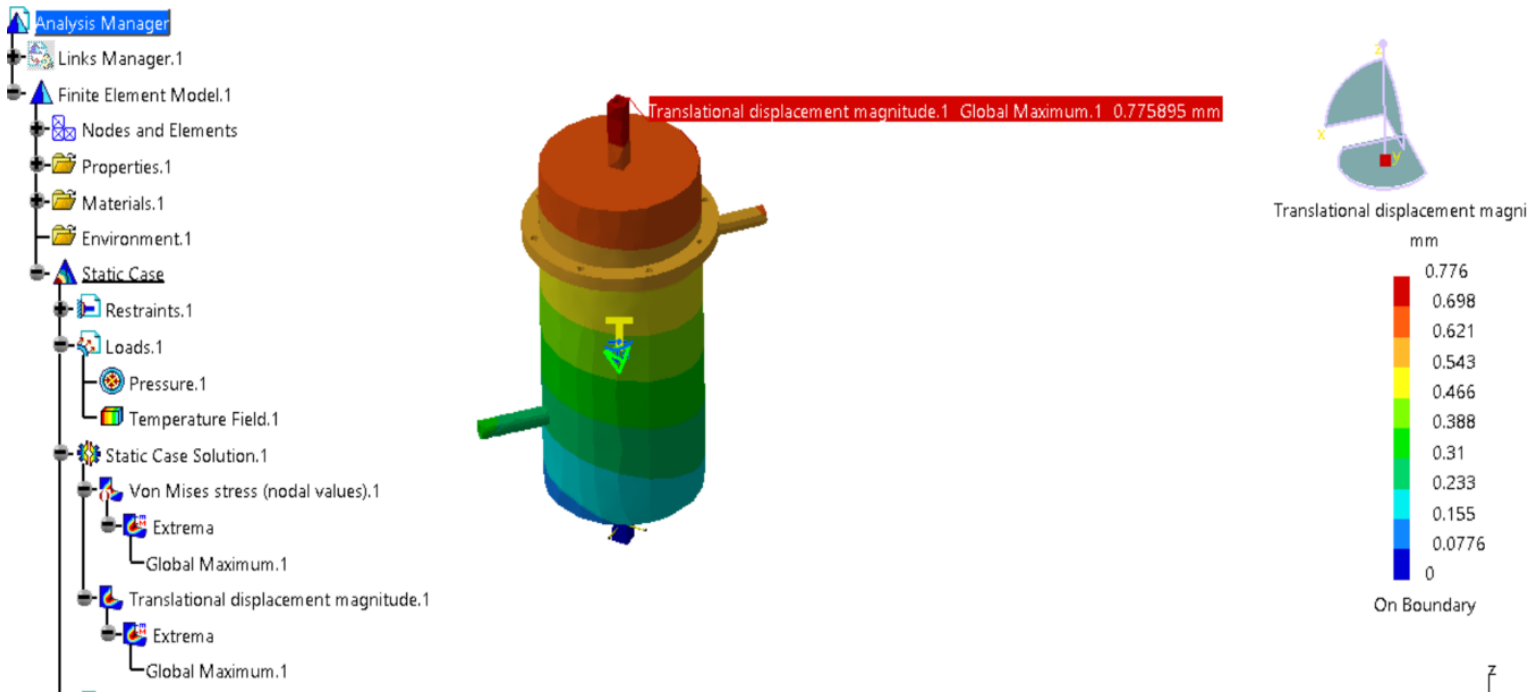

Gambar 4. Translational displacement yang terjadi pada desain bejana molecular sieve

Pengujian secara simulasi dilakukan dengan memvariasikan temperatur mulai dari $30^{\circ} \mathrm{C}$ sampai dengan $150{ }^{\circ} \mathrm{C}$ serta tekanan bervariasi mulai dari 10 bar sampai dengan
70 bar diperoleh data hasil pengujian sebagai berikut :

Tabel 2. Hasil pengujian secara simulasi menggunakan software CATIA

\begin{tabular}{rrrcr}
\hline No. & $\begin{array}{r}\text { Tekanan } \\
\text { (bar) }\end{array}$ & $\begin{array}{c}\text { Temperatur } \\
\left({ }^{\circ} \mathrm{C}\right)\end{array}$ & $\begin{array}{c}\text { Tegangan mekanik } \\
\text { maksimal } \\
\left(\mathrm{N} / \mathrm{m}^{2}\right)\end{array}$ & $\begin{array}{c}\text { Translational } \\
\text { displacement maksimal } \\
(\mathrm{mm})\end{array}$ \\
\hline 1 & 10 & 30 & $1,4869 \mathrm{E}+07$ & 0,0966 \\
2 & 10 & 60 & $1,4869 \mathrm{E}+07$ & 0,4582 \\
3 & 10 & 90 & $1,4869 \mathrm{E}+07$ & 0,8199 \\
4 & 10 & 120 & $1,4869 \mathrm{E}+07$ & 1,1815 \\
5 & 10 & 150 & $1,4869 \mathrm{E}+07$ & 1,5431 \\
6 & 30 & 30 & $4,4608 \mathrm{E}+07$ & 0,0869 \\
7 & 30 & 60 & $4,4608 \mathrm{E}+07$ & 0,4143 \\
8 & 30 & 90 & $4,4608 \mathrm{E}+07$ & 1,13759 \\
9 & 30 & 120 & $4,4608 \mathrm{E}+07$ & 1,4991 \\
10 & 30 & 150 & $4,4608 \mathrm{E}+07$ & 0,0957 \\
11 & 50 & 30 & $7,4347 \mathrm{E}+07$ & 0,3704 \\
12 & 50 & 60 & $7,4347 \mathrm{E}+07$ & 0,7319 \\
13 & 50 & 90 & $7,4347 \mathrm{E}+07$ & 1,0936 \\
14 & 50 & 120 & $7,4347 \mathrm{E}+07$ & 1,4551 \\
15 & 50 & 150 & $7,4347 \mathrm{E}+07$ & 0,1170 \\
16 & 70 & 30 & $1,0409 \mathrm{E}+08$ & 0,3502 \\
17 & 70 & 60 & $1,0409 \mathrm{E}+08$ & 0,6880 \\
18 & 70 & 90 & $1,0409 \mathrm{E}+08$ & 1,0496 \\
19 & 70 & 120 & $1,0409 \mathrm{E}+08$ & 1,4112 \\
20 & 70 & 150 & $1,0409 \mathrm{E}+08$ & \\
\hline
\end{tabular}


Tegangan mekanik terbesar terjadi pada bagian body/shell bejana molecular sieve dengan tegangan mekanik 1,0409 $\mathrm{x}$ $10^{8} \mathrm{~N} / \mathrm{m}^{2}$ pada 70 bar dan temperatur 150 ${ }^{\circ} \mathrm{C}$. Hal ini terjadi karena pada bagian tersebut dipasangkan support untuk menjaga posisi bejana molecular sieve statis.

Hasil pengujian translational displacement pada desain bejana molecular sieve menghasilkan translational displacement terbesar terjadi pada bagian tutup bejana molecular sieve sebesar 1,4112 mm pada pengujian secara simulasi dengan tekanan 70 bar dan temperatur $150{ }^{\circ} \mathrm{C}$ seperti ditunjukkan pada Tabel 2. Maka direkomendasikan support pemipaan pada bagian body/shell dari desain bejana molecular sieve yang bisa memberikan kebebasan bergerak ke arah vertikal ke atas untuk menanggulangi translational displacement yang terjadi.

Hasil pengujian secara simulasi menunjukkan pada tekanan 70 bar dan temperatur $150{ }^{\circ} \mathrm{C}$ tegangan mekanik yang dihasilkan sebesar $1,0409 \times 10^{8} \mathrm{~N} / \mathrm{m}^{2}$ belum melebihi dari yield strenght material stainless steel 304 sebesar $1,7 \times 10^{9} \mathrm{~N} / \mathrm{m}^{2}$. Tegangan mekanik tersebut masih berada di daerah elatis material yang digunakan. Translational displacement terbesar yang terjadi pada desain bejana molecular sieve sangat kecil $(1,4112 \mathrm{~mm})$ sehingga tidak mengakibatkan perubahan bentuk pada desain bejana molecular sieve. Hasil tersebut diperoleh dengan desain bejana molecular sieve pada bagian body/shell diklem statis tetapi masih memberikan kebebasan bergerak ke arah vertikal.

Untuk mengetahui terjadinya kerusakan pada desain bejana molecular sieve, maka dilakukan simulasi diluar rencana seperti di dalam metodologi. Simulasi tersebut adalah dengan menaikkan tekanan hingga 140 bar dan temperatur hingga $150{ }^{\circ} \mathrm{C}$. Hasil pengujian secara simulasi mendapatkan tegangan mekanik yang dihasilkan sebesar 2,0817 x $10^{8} \mathrm{~N} / \mathrm{m}^{2}$ dan translational displacement sebesar 1,2574 mm. Tegangan mekanik tersebut telah melebihi yield strenght material stainless steel 304 dan berada didaerah plastis material. Sehingga pada tekanan 140 bar dan temperatur $150{ }^{\circ} \mathrm{C}$ bejana molecular sieve telah mengalami kerusakan.

Pada tekanan 30 bar dan temperatur $120{ }^{\circ} \mathrm{C}$ (tekanan dan temperatur operasional), tegangan mekanik yang terjadi sebesar 4,4608 $\times 10^{7} \mathrm{~N} / \mathrm{m}^{2}$ lebih kecil daripada yield strenght material Stainless Steel 304 dan berada didaerah elastis material. Sedangkan translational displacement sebesar $1,1375 \mathrm{~mm}$ sangat kecil jika dibandingkan dengan dimensi bejana molecular sieve. Dengan demikian bejana molecular sieve aman untuk dioperasikan guna mendukung penelitian. 


\section{KESIMPULAN}

Desain bejana molecular sieve menggunakan material stainless steel 304 serta diklem statis pada bagian body /shell. Melalui pengujian secara simulasi menggunakan software CATIA diperoleh pada tekanan 30 bar dan temperatur $120{ }^{\circ} \mathrm{C}$ tegangan mekanik yang dihasilkan sebesar $4,4608 \times 10^{7} \mathrm{~N} / \mathrm{m}^{2}$ lebih kecil daripada yield strenght material stainless steel 304 dan berada di daerah elastis material. Sedangkan translational displacement sebesar 1,1375 mm sangat kecil jika dibandingkan dengan dimensi bejana molecular sieve sehingga tidak mengakibatkan perubahan bentuk. Dengan demikian bejana molecular sieve aman untuk dioperasikan guna mendukung penelitianpemurnian helium.

\section{UCAPAN TERIMAKASIH}

Kami ucapkan terima kasih kepada Program Insinas Flagship RISTEK DIKTI 2019 yang telah membiayai penelitian. Juga kepada Kepala Pusat Teknologi dan Keselamatan Reaktor Nuklir (PTKRN) dan Kepala BPFKR selaku atasan langsung serta teman-teman Subbidang Fasilitas Termohidrolika.

\section{DAFTAR PUSTAKA}

[1] SITI ALIMAH, SRIYONO, Kajian Sitem Pemurnian Helium Reaktor HTGR Berdaya Kecil, Jurnal
Pengembangan Energi Nuklir Vol. 18 No. 2 (2016)

[2] HAMAMOTO, S., et al., Investigation of chemical characteristics of primary helium gas coolant of HTTR (high temperature engineering test reactor). Nuclear Engineering and Design, 2014. 271: p. 487-491.

[3] FANG, C., et al., The R\&D of HTGR high temperature helium sampling loop: From HTR-10 to HTR-PM. Nuclear Engineering and Design, 2016. 306: p. 192-197.

[4] ATIQAH M, HILDA, SRIYONO, MIA K., Pemodelan dan Simulasi Proses Adsorpsi Gas Pengotor oleh Molecular Sieve pada Pendingin RDE dengan Software ChemCad, Prosiding Seminar Nasional TEKNOKA ke-3, 2018

[5] SANTOS, M.G.R.S., et al., Natural gas dehydration by molecular sieve in offshore plants: Impact of increasing carbon dioxide content. Energy Conversion and Management, 2017. 149: p. 760-773.

[6] QIAN, X., et al., Experimental investigation on cryogenic hydrogen adsorption of molecular sieves. Fusion Engineering and Design, 2012. 87(4): p. $359-362$.

[7] AHMED, M.J. and S.K. THEYDAN, Modeling of propane separation from light hydrocarbons by adsorption on 
4A molecular sieve zeolite. Journal of Natural Gas Science and Engineering, 2014. 18: p. 1-6.

[8] ARIFAL, SRIYONO, dan SUMIJANTO, Analisis Pengaruh Tekanan dan Temperatur Terhadap Proses Penyaringan $\mathrm{CO}_{2}$ dan $\mathrm{H}_{2} \mathrm{O}$ Pada Molecular Sieve. SIGMA EPSILON-Buletin Ilmiah Teknologi Keselamatan Reaktor Nuklir, 2012. 16(3-4).

[9] PINEM, M.D., CATIA Si Jago Desain Tiga Dimensi, 2009, Kawah Media, Jakarta.

[10] HARYANTO;, D. and K. SANTOSA. Analisis Tegangan Mekanik Dan Translational Displacement Pada Struktur Experiment Kanal. in Seminar Nasional Teknologi Energi Nuklir 2015. Bali, 15-16 Oktober 2015 .

[11] HARYANTO, D. dan HISTORI, Pengujian Kekuatan Mekanik Pada Support Perangkat Sumber Pemanas. SIGMA EPSILON-Buletin Ilmiah Teknologi Keselamatan Reaktor Nuklir, 2011. 15(1).

[12] SAINI, M., et al., Mechanical Properties of Bimetallic Weld Joint between SA 516 Grade 65 Carbon Steel and SS 304 L For Steam Generator Application. life, 2014. 4: p. 8. 